\title{
DESIGN, DEVELOPMENT, AND CHARACTERIZATION OF OROMUCOSAL WAFER OF TRAMADOL HYDROCHLORIDE
}

\author{
RITA N WADETWAR*, TEJASWINI CHARDE \\ Department of Pharmaceutical Sciences, Rashtrasant Tukadoji Maharaj, Nagpur University, Nagpur, Maharashtra, India \\ Email: rnwadetwar@gmail.com
}

Received: 07 March 2018, Revised and Accepted: 23 April 2018

\section{ABSTRACT}

Objective: The objective of the present work was the preparation of fast-dissolving film of Tramadol $\mathrm{HCl}$ (TMH) using water-soluble polymer, to achieve faster onset of action, to improve patient compliance, ease of dosing, and bypass the first-pass metabolism.

Methods: TMH oromucosal wafers were prepared using pullulan as natural, biodegradable polymer, and propylene glycol as plasticizer by solvent casting method. Formulation batches were prepared using $3^{2}$ full-factorial designs. The prepared TMH oromucosal wafers were characterized for morphology, uniformity of weight, drug content, folding endurance, in vitro disintegration time (DT), \% moisture content, surface pH, in vitro \% drug release, ex vivo permeation studies, compatibility studies (differential scanning calorimetry, Fourier transform infrared spectroscopy, and X-ray diffraction), and stability studies.

Results: Optimized batch of mouth-dissolving film of TMH containing pullulan as polymer showed $98.67 \pm 0.11 \%$ drug release at 6 min. It showed better Folding endurance was observed to be 88 , in vitro DT $5.11 \mathrm{~s}$, surface pH $6.84 \pm 0.12 \mathrm{pH}$, thickness $0.17 \pm 0.11 \mathrm{~mm}$, and percentage content uniformity $98.45 \pm 0.48 \%$. Stability studies carried out for the best formulation FDF5 revealed that the formulation was stable.

Conclusion: The results obtained in this research work clearly indicated a promising potential of fast-dissolving oral films using natural biodegradable polymer, pullulan which gave rapid drug delivery and rapid onset of action of centrally acting drug, TMH for patients suffering from pain.

Keywords: Wafers, Tramadol HCl, pullulan, Solvent casting method.

(C) 2018 The Authors. Published by Innovare Academic Sciences Pvt Ltd. This is an open access article under the CC BY license (http://creativecommons. org/licenses/by/4. 0/) DOI: http://dx.doi.org/10.22159/ajpcr.2018.v11i8.25709

\section{INTRODUCTION}

Fast-dissolving film technology is a new drug delivery system that provides a very convenient means of taking medication and supplements. It is an alternative to conventional dosage forms for pediatric and geriatric patients who experience difficulties in swallowing traditional oral solid-dosage forms such as tablet and capsule. Through the buccal and sublingual administration of drug, solutes are rapidly absorbed into the systemic circulation. Buccal and sublingual route provides direct entry of drug into the systemic circulation, thereby avoiding the hepatic first-pass effect. It offers higher permeability to many drugs. Difficulty in swallowing (dysphasia) is a common problem of all age groups, especially elderly and pediatrics, because of physiological changes associated with this group of patients. Buccal and sublingual drug delivery systems dissolve or disintegrate in the mouth rapidly, without the need of water. Oral administration is the most popular route due to ease of ingestion, pain avoidance, and versatility, and most importantly, patient's compliance [1]. Oral route still remains the favorite route of drug administration in many diseases, and still today, it is the first way investigated in the development of new dosage form [2]. Oral disintegrating film or wafer can be defined as a dosage form that employs a water-dissolving polymer which allows the dosage form to quickly hydrate by saliva, adhere to mucosa, and disintegrate within $30 \mathrm{~s}$, dissolves and releases medication for oromucosal absorption when placed on the tongue or oral cavity. It gives faster onset of action, has improved patient compliance and ease of dosing for the patient, and bypass the first-pass metabolism [3,4]. Tramadol $\mathrm{HCl}(\mathrm{TMH})$ is a centrally acting synthetic opioid analgesic. Although its mode of action is not completely understood, from animal tests, at least two complementary mechanisms appear applicable: Binding of parent and M1 metabolite to $\mu$-opioid receptors and weak inhibition of reuptake of norepinephrine and serotonin.
Rational of the present work is to formulate fast-dissolving film of TMH using natural polymer pullulan, with special emphasis on, increasing the bioavailability of drug and to provide immediate action of centrally acting analgesic drug, for pain relief.

\section{METHODS}

Materials

TMH was obtained as gift sample from Zim laboratories, Kalmeshwar. Pullulan was obtained from Gangawal Chemicals, Mumbai. Propylene glycol, citric acid, and mannitol were procured from SD Fine Chemicals Ltd, Mumbai, India. All other reagents used were of analytical grade. Purified water was used for the study.

\section{Preformulation studies}

Preformulation may be described as a phase of the research and development process where the formulation scientist characterizes the physical, chemical, and mechanical properties of new drug substances, to develop stable, safe, and effective dosage forms. During this evaluation, possible interaction with various inert ingredients intended for use in the final dosage form is also studied.

\section{Calibration curve of TMH in phosphate buffer pH 6.8}

Stock solution of TMH was prepared by dissolving $10 \mathrm{mg}$ of TMH in $100 \mathrm{ml}$ of phosphate buffer $\mathrm{pH} 6.8$ to get $100 \mu \mathrm{g} / \mathrm{ml}$. Ultraviolet (UV) absorption of the prepared solutions was performed at $\lambda_{\max } 272 \mathrm{~nm}$ $[5,6]$. The calibration curve was used for the estimation of drug content in formulation and ex-vivo diffusion studies.

\section{Drug-excipient compatibility study}

Excipients are important components of almost all pharmaceutical dosage forms. The successful formulation of a stable and effective solid 
dosage form depends on the careful selection of the excipients, which are added to facilitate administration, to promote the consistent release and bioavailability of the drug, and protect it from degradation $[7,8]$. TMH along with excipients in 1:1 ratios were kept in the stability chamber at accelerated stability condition at $40^{\circ} \mathrm{C} \pm 2^{\circ} \mathrm{C}$ temperature and $75 \pm 5 \%$ relative humidity for 1 month. The samples were withdrawn at the end of a month and evaluated for compatibility studies by differential scanning calorimetry (DSC) and Fourier transform infrared spectroscopy (FTIR).

\section{Drug-excipient compatibility studies by DSC}

DSC thermogram of TMH and physical mixture of TMH and polymer were performed using a DSC instrument (Mettler DSC 1 star system, Metler-Toledo, Switzerland). The thermal behavior was studied by heating 3-5 mg of each sample in aluminum-crimped pans under nitrogen gas flow $\left(20 \mathrm{ml} / \mathrm{min}^{-1}\right)$ at a scanning rate of $10^{\circ} \mathrm{C} \mathrm{min}-1$ over a temperature range of $30-300^{\circ} \mathrm{C}$.

\section{Drug-excipient compatibility studies by FTIR}

It is the analytical techniques that offer the possibilities of chemical identifications of the drugs. The drug-excipient compatibility study was carried out using FTIR.

\section{X-ray powder diffraction (XRPD) studies}

Molecular properties on complexation were studied by XRPD of TMH. The crystallinity of samples was analyzed by XRPD using Bruker diffractometer (WI 1140, Japan) and Cu-Ká radiation. The diffractograms were run at $2.5^{\circ} \mathrm{C} / \mathrm{min}$ and at chart speed of $2^{\circ} / 2 \mathrm{~cm}$.

\section{Formulation of fast-dissolving film}

Preparation of fast-dissolving film

Fast-dissolving film of TMH was prepared by solvent casting technique. The film was prepared using polymer, pullulan. Propylene glycol was used as plasticizer. Polymer was dispersed in a measured quantity of solvent. The drug was added to the above solution. To this solution, all other excipients were added with continuous stirring. The thick, viscous solution was degassed to remove entrapped air by ultrasonication. The solution was then casted on glass plate of film former machine (VJ instruments) and was allowed to dry [9]. The duration of drying depended on the properties of each polymer. Individual films were prepared by cutting the films into strips of regular dimension of $2 \mathrm{~cm}$ $\times 2 \mathrm{~cm}$ with a stainless steel cutter. The samples were packed in a highdensity polyethylene sheet, sealed and stored in desiccators at room temperature [10]. Formulation of different batches is shown in Table 1.

\section{Dose calculation}

The dose of TMH is $50 \mathrm{mg}$. Therefore, the amount of TMH required in 4 $\mathrm{cm}^{2}$ of film is $50 \mathrm{mg}$.

\section{Area of square $=(\text { side })^{2}$}

$$
=(7)^{2}
$$

$$
=49.00 \mathrm{~cm}^{2}
$$

Area of film $=2 \mathrm{~cm} \times 2 \mathrm{~cm}=4 \mathrm{~cm}^{2}$

$4 \mathrm{~cm}^{2}$ contains $50 \mathrm{mg}$

(49.00) $\mathrm{cm}^{2}$ contains $=612.5 \mathrm{mg}$ of TMH [11].

\section{Experimental design}

The objective of the present investigation was to observe the combined effect of the concentration of polymer as well as the concentration of plasticizer on the disintegration time (DT), in vitro \% drug release and folding endurance for obtaining the optimized fast-dissolving film.

Experimental design was generated by Design-Expert ${ }^{\circledR}$ 8.0.7.1 software. In this work, a $3^{2}$ factorial design was used for the optimization of fast-dissolving film. A 2-factor was evaluated each at three levels and experimental trials were performed on all nine combinations. A statistical model incorporating interactive and polynomial terms were used to evaluate the response using the Equation

$\mathrm{Y}=\mathrm{b}^{0}+\mathrm{b}_{1} \mathrm{X}_{1}+\mathrm{b}_{2} \mathrm{X}_{2+} \mathrm{b}_{12} \mathrm{X}_{1} \mathrm{X}_{2}+\mathrm{b}_{11} \mathrm{X}_{1}^{2}+\mathrm{b}_{22} \mathrm{X}_{2}^{2}$

where $\mathrm{Y}$ is the dependent variable, $\mathrm{b}^{0}$ is the arithmetic mean response of the nine runs, and $b_{1}$ is the estimated coefficient for the factor $X_{1}$. The main effects $\left(\mathrm{X}_{1}\right.$ and $\left.\mathrm{X}_{2}\right)$ represent the average result of changing one factor at a time from its low to high value.

The interaction terms $\left(\mathrm{X}_{1} \mathrm{X}_{2}\right)$ show how the response changes when two factors are simultaneously changed. The polynomial terms $\left(\mathrm{X}_{1}{ }^{2}\right.$ and $\mathrm{X}_{2}^{2}$ ) are included to investigate nonlinearity. The above equation indicates a coefficient with negative sign which shows that there is an increase in response when factor level is decreased from higher to lower level and the factor with higher absolute value of coefficient and lower value "p" has major effect on the response variables. A $3^{2}$ randomized full factorial design was utilized to study systematically the effects of two independent factors on the characteristics of the film. In this design, two factors are evaluated, each at three levels and experimental trials were carried out on all nine possible combinations [12,13].

\section{Evaluation of fast-dissolving film}

\section{Physical appearance and surface texture}

This parameter was checked simply by visual inspection of films and evaluation of texture by feel or touch [14].

\section{Uniformity of weight}

The film $\left(4 \mathrm{~cm}^{2}\right)$ was cut at three different places. The weight of each film strip was taken on a digital weighing balance. Average weight and weight variation were calculated [14].

\section{Drug content}

The area of $2 \mathrm{~cm} \times 2 \mathrm{~cm}\left(4 \mathrm{~cm}^{2}\right)$ of the prepared film was dissolved in $100 \mathrm{ml}$ of simulated saliva with occasional shaking. The solution was filtered to remove insoluble residue. The absorbance was measured on double-beam UV spectrophotometer (Shimadzu UV-1700) at $272 \mathrm{~nm}[14]$.

\section{Folding endurance}

It was measured manually for the prepared fast-dissolving film $2 \mathrm{~cm}$ $\times 2 \mathrm{~cm}\left(4 \mathrm{~cm}^{2}\right)$. A strip was repeatedly folded at the same place till it broke. The number of times the film could be folded at the same place without breaking gave the value of folding endurance [15].

\begin{tabular}{|c|c|c|c|c|c|}
\hline Formulation Code & Drug (mg) & Pullulan $(\% \mathrm{w} / \mathrm{w})$ & Propylene glycol $(\% \mathrm{w} / \mathrm{w})$ & Mannitol (mg) & Citric acid (mg) \\
\hline FDF1 & 612.5 & 10 & 7.5 & 120 & 120 \\
\hline FDF2 & 612.5 & 12.5 & 5 & 120 & 120 \\
\hline FDF3 & 612.5 & 12.5 & 10 & 120 & 120 \\
\hline FDF4 & 612.5 & 7.5 & 7.5 & 120 & 120 \\
\hline FDF5 & 612.5 & 7.5 & 5 & 120 & 120 \\
\hline FDF6 & 612.5 & 7.5 & 10 & 120 & 120 \\
\hline FDF7 & 612.5 & 10 & 10 & 120 & 120 \\
\hline FDF9 & 612.5 & 10 & 5 & 120 & 120 \\
\hline
\end{tabular}

Table 1: Formulation of different batches of TMH film

TMH: Tramadol HCl 


\section{In vitro $\mathrm{DT}$}

DT gives an indication about the disintegration characteristics and dissolution characteristics of the film. The film size required for dose delivery $(2 \mathrm{~cm} \times 2 \mathrm{~cm}$ ) was placed on a stainless steel wire mesh placed in a Petri dish containing $10 \mathrm{ml}$ phosphate buffer $\mathrm{pH} 6.8$ at $37^{\circ} \mathrm{C}$. Time required for the film to break was noted as in vitro DT. This test was performed on three films of each formulation [15].

\section{$\%$ Moisture content}

This test was also carried to evaluate the integrity of films at the dry condition. Film of $4 \mathrm{~cm}^{2}$ area was cut and weighed accurately and kept in a desiccator containing activated silica. The films were weighed regularly until a constant weight was obtained. Percentage moisture content of film was determined as follows.

Percent moisture content=(Initial weight-Final weight/Final weight) $\times 100[14]$

\section{Surface $\mathbf{p H}$}

Surface $\mathrm{pH}$ of the film was determined to investigate the possible side effects due to change in $\mathrm{pH}$ in vivo since an acidic or alkaline $\mathrm{pH}$ may cause irritation to the buccal mucosa. The film was placed in a Petri dish and moistened with $1 \mathrm{ml}$ of distilled water and kept for $1 \mathrm{~h} . \mathrm{pH}$ was noted with the electrode of the $\mathrm{pH}$ meter. The average of three determinations for each formulation was done [16].

\section{In vitro dissolution study}

The phosphate buffer $\mathrm{pH} 6.8$ was taken as the dissolution medium to determine the drug release. The dissolution profile of quick release films of TMH was carried out in USP Type I (basket apparatus) (Electrolab, Mumbai) containing $300 \mathrm{ml}$ of the phosphate buffer $\mathrm{pH}$ 6.8. The film was placed in the basket, maintained at $37 \pm 0.5^{\circ} \mathrm{C}$ and the agitation speed was $50 \mathrm{rpm}$. Aliquots $(5 \mathrm{ml})$ of the dissolution medium were withdrawn at $0,1,2,3,4,5$, and 6 min time intervals and the same amount was replaced with the fresh medium. Samples were assayed spectrophotometrically at $272 \mathrm{~nm}$. The cumulative percentage drug release was expressed as each value is the mean $\pm \mathrm{SD}$, $\mathrm{n}=3$ determinations $[17,18]$.

\section{Ex vivo permeation studies through goat buccal mucosa}

Permeation studies were carried using the modified Franz diffusion cell of internal diameter $2.5 \mathrm{~cm}$. The buccal mucosa of the freshly killed goat was used as the model membrane. The buccal pouch of the freshly killed goat was procured from the local slaughterhouse. The buccal mucosa was excised and trimmed evenly from the sides and then washed in 6.8 phosphate buffer and used immediately. The membrane was stabilized before mounting to remove the soluble components. The mucosa was mounted between the donor and receptor compartments. The receptor compartment was filled with $33 \mathrm{ml}$ of 6.8 phosphate buffer which was maintained at $37^{\circ} \mathrm{C} \pm 0.2^{\circ} \mathrm{C}$ and the hydrodynamics were maintained by stirring with a magnetic bead at $50 \mathrm{rpm}$. Previously weighed film of dimensions $2 \mathrm{~cm} \times 2 \mathrm{~cm}$ was placed in intimate contact with the mucosal surface of the membrane which was previously moistened with a few drops of simulated saliva. From receptor compartment, $1 \mathrm{ml}$ sample was withdrawn at suitable time interval which was then replaced with $1 \mathrm{ml}$ of 6.8 phosphate buffer. The percentage of drug permeated was determined by measuring the absorbance in a UVvisible spectrophotometer at $272 \mathrm{~nm}[11,19]$.

\section{Stability study}

Stability study of fast-dissolving film was carried out on optimized formulation. The formulation prepared was packed in a special way. The formulation was wrapped in a butter paper followed by aluminum foil. This was packed in an aluminum pouch and heat sealed and stored in desiccator at $40^{\circ} \mathrm{C} \pm 2{ }^{\circ} \mathrm{C} / 75 \% \pm 5 \% \mathrm{RH}$. Formulations were stored for 2 months. During the course of stability study, the samples were withdrawn after suitable time intervals and films were evaluated for physical appearance, DT, folding endurance, drug content, and in vitro drug release studies [20].

\section{RESULTS AND DISCUSSION}

\section{Drug-excipient compatibility studies by FT-IR}

Drug TMH showed sharp characteristic peak at $1288.45 / \mathrm{cm}$ (C-O stretching), $1577.77,1606.70 / \mathrm{cm}$ (C=C stretching), $1006.84 / \mathrm{cm}$ (C-O Stretching [alcohol]), 1242.68/cm (C-N Stretching), 702.09 $\mathrm{cm}$ (C-H Stretching), and 3304.06/cm (O-H Stretching). The peaks observed in the spectra of pure drug (Fig. 1) correlates with peaks observed in the spectra of physical mixture, containing pure drug and excipients (Fig. 2). This suggests that the drug, TMH is compatible with excipients. From these, it can be concluded that the drug has maintained its identity without losing its characteristic properties. It will not show any adverse effect in action of the formulation and helps to study desire parameters in the present study.

\section{Drug excipients compatibility study by DSC}

TMH showed a sharp endothermic peak at $184.15^{\circ} \mathrm{C}$ corresponding to its melting point as shown in Fig. 3. Similarly, the physical mixture of TMH with pullulan showed intense peak at $167.78^{\circ} \mathrm{C}$ as shown in Fig. 4. Slight shifting of melting endothermic peak of TMH in the physical mixture indicated that there is no interaction between drug and the excipients. DSC thermograph of optimized film did not show any melting endotherm for drug as shown in Fig. 5. This could be due to the conversion of drug to its amorphous form which can be attributed to the process of complexation or the components of the film such as polymer and other excipients are known as crystallization inhibitor.

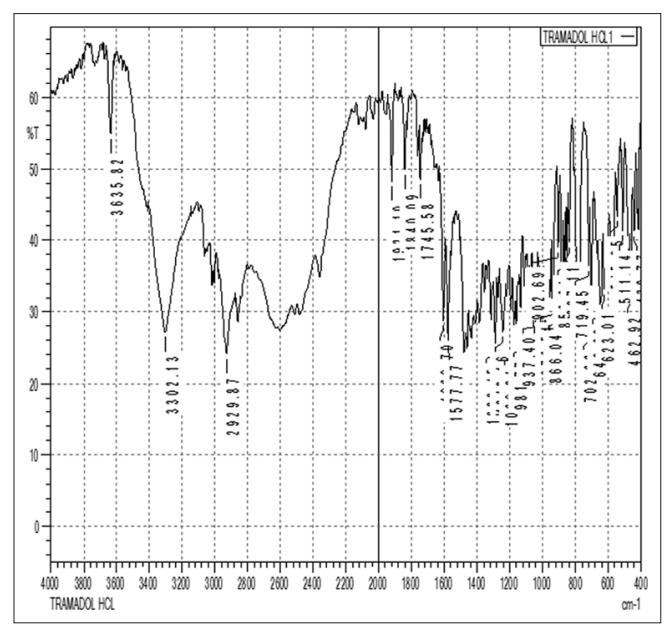

Fig. 1: Infrared spectroscopy spectra of TMH

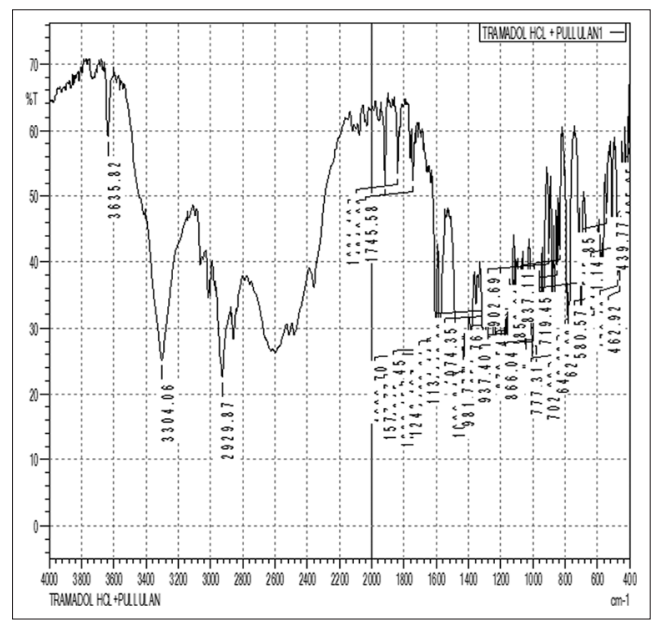

Fig. 2: Infrared spectroscopy spectra of $\mathrm{TMH}+$ pullulan 


\section{XRPD studies of TMH}

Every crystalline drug has a characteristic X-ray diffraction (XRD) pattern which can be used like fingerprint for its identification. XRD technique was employed to identify crystallographic properties of drug. The X-ray diffractograms of TMH confirms its crystalline nature, as evidenced from the number of sharp and intense peaks situated between $1^{\circ}$ and $2^{\circ}(2 \theta)$ due to its crystalline nature as shown in Fig. 6. The intensity of the peak was reduced, when the drug was encapsulated

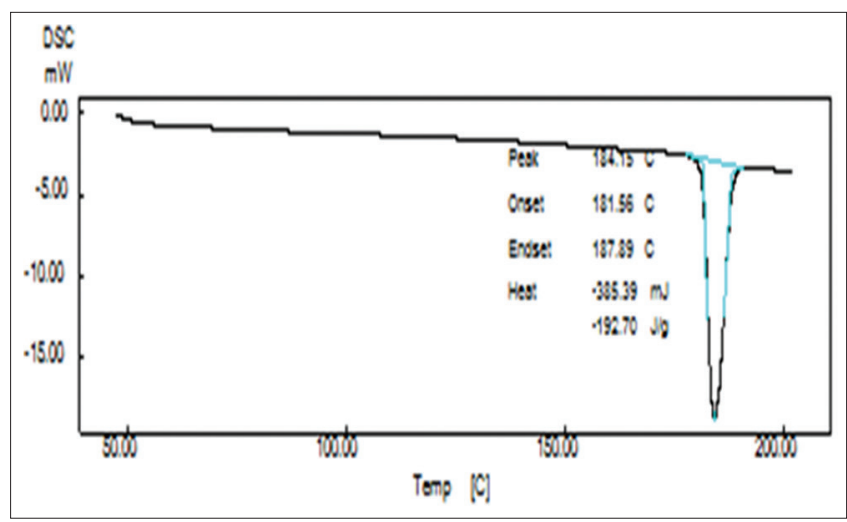

Fig. 3: Differential scanning calorimetry thermogram of TMH

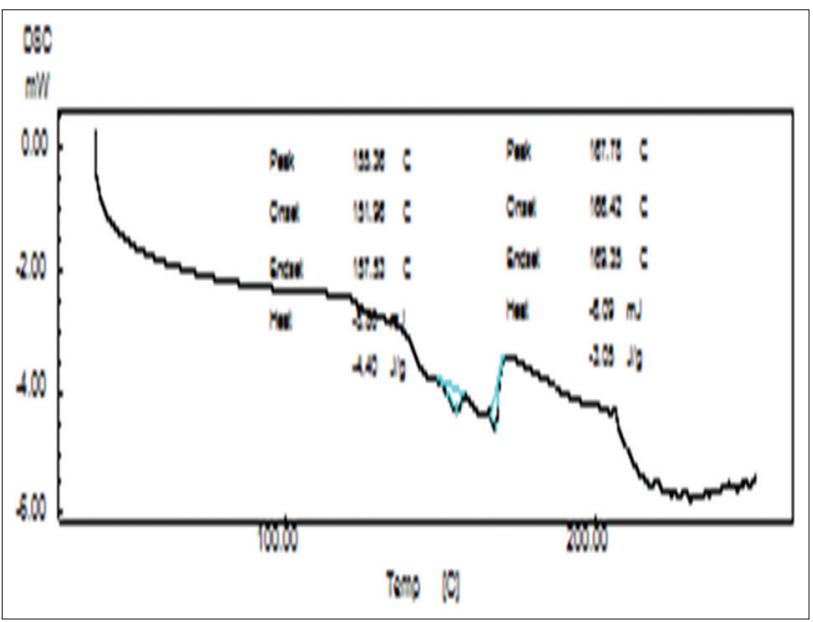

Fig. 4: Differential scanning calorimetry thermogram of TMH+pullulan

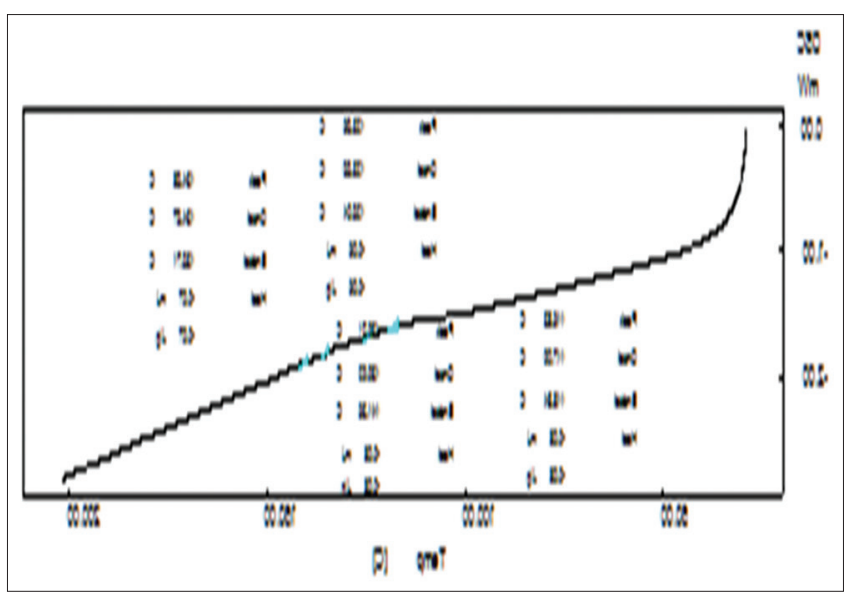

Fig. 5: Differential scanning calorimetry thermogram of optimized batch in polymer which indicated the reduction in crystallinity of TMH as shown in Fig. 7. The decrease in crystallinity also confirmed the physical stability of the drug. Signal intensities were very weak in the optimized batch, which indicated that most of the drug had dispersed at a molecular level in the polymeric matrices with no indication of crystalline nature of the drug in the matrices.

\section{Optimization of fast-dissolving film by factorial design}

The two-independent variables such as pullulan $\left(\mathrm{X}_{1}\right)$ and propylene glycol $\left(\mathrm{X}_{2}\right)$ were selected on the basis of the preliminary studies carried out before the experimental design is being implemented, whereas DT, folding endurance, and in vitro \% drug release were then dependent variables. The concentration of pullulan and propylene glycol were kept as $7.5 \%, 10 \%, 12.5 \%$, and $5 \%, 7.5 \%, 10 \%$, respectively.

\section{Response surface plots}

The response surface plots were generated using Design Expert 8.0.7.1 software so as to observe the effects of independent variables on the response studied such as DT, folding endurance, and in vitro \% drug release. The response surface plots showed that various combinations of independent variables $\mathrm{X}_{1}$ and $\mathrm{X}_{2}$ may satisfy any specific requirement (i.e., DT, in vitro \% drug release, and folding endurance) while taking into consideration the various factors involved in the dosage form. In vitro $\%$ drug release was found to decrease with increase in concentration of pullulan as well as propylene glycol as shown in Fig. 8. DT was found to increase with an increase in the concentration of pullulan as shown in Fig. 9. Folding endurance increased with decrease in concentration of pullulan as shown in Fig. 10. Furthermore, DT and folding endurance

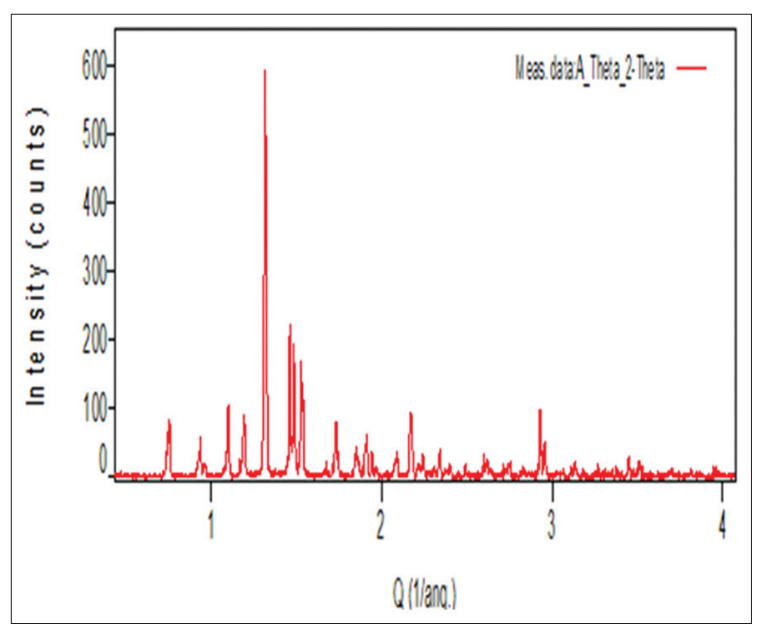

Fig. 6: X-ray diffraction of TMH

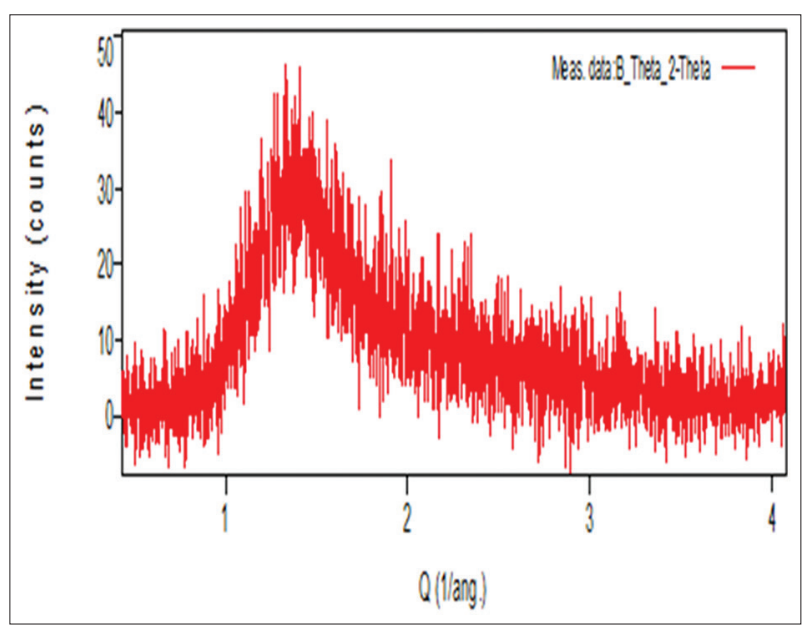

Fig. 7: X-ray diffraction of optimized batch 
was found to change with the change in concentration of propylene glycol.

\section{Evaluation of fast-dissolving film}

The prepared fast dissolving films were evaluated for following parameters

\section{Physical appearance and surface texture of film}

The appearance of all the films was transparent and uniform. The observation suggests that the films had smooth surface and they were elegant enough to see.

\section{Thickness}

Thickness of the film was found to be between $0.17 \pm 0.1 \mathrm{~mm}$ and

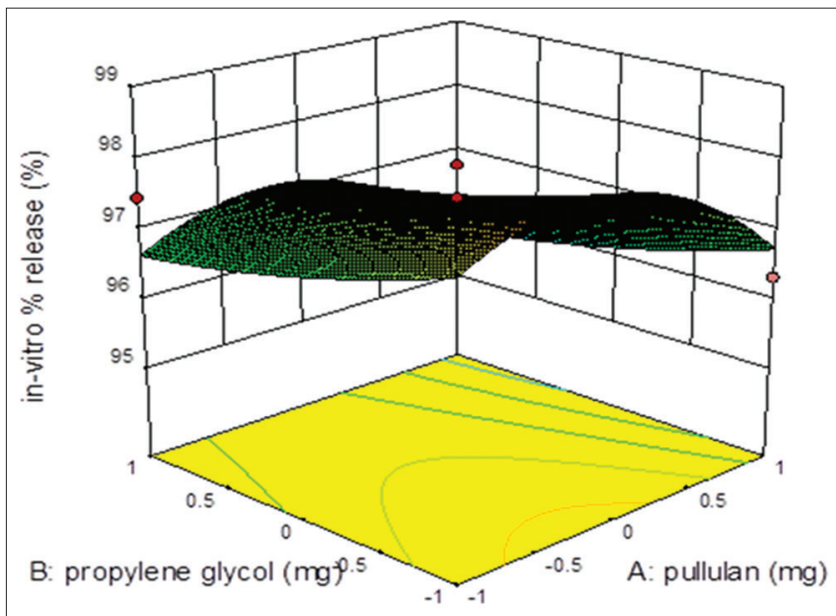

Fig. 8: Response surface plot for in vitro \% drug release

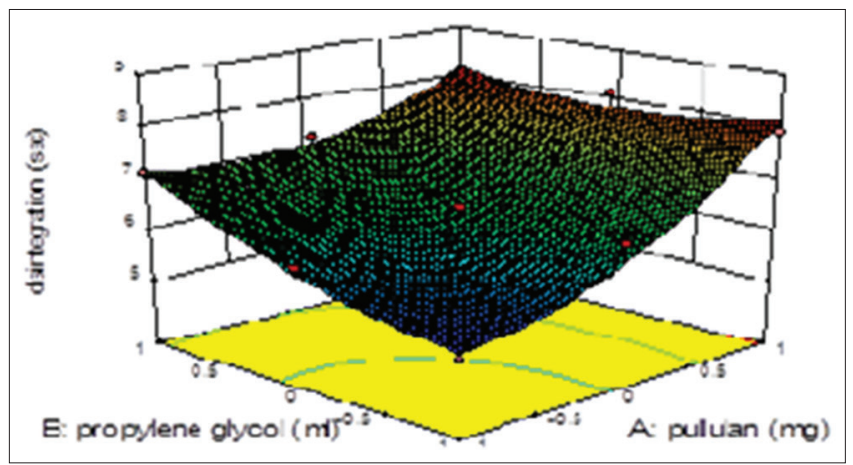

Fig. 9: Response surface plot for disintegration time

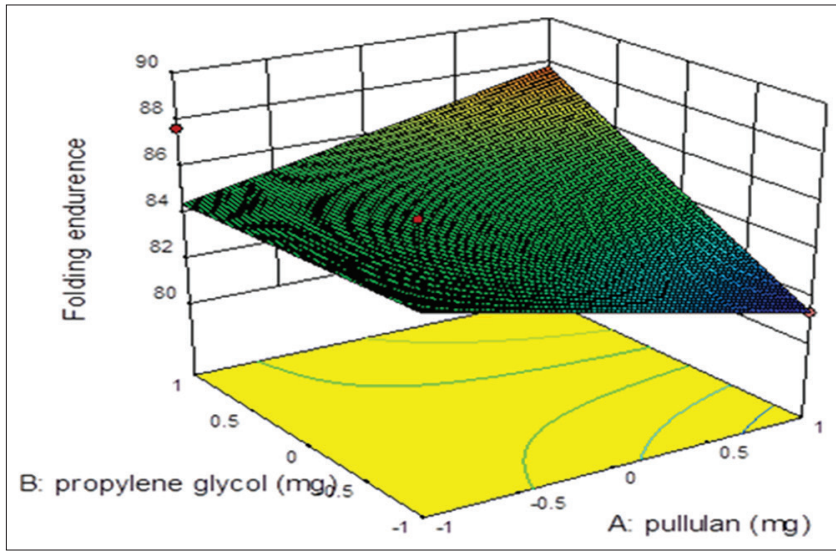

Fig. 10: Response surface plot for folding endurance
$0.29 \pm 0.2 \mathrm{~mm}$. A very low standard deviation value indicates that the method used for the formulation of the film is reproducible and give film of uniform thickness and hence dosage accuracy in each film can be ensured. The results are shown in Table 2 .

\section{Surface $\mathbf{p H}$}

Surface $\mathrm{pH}$ of all films was found to be in the range of $6.53 \pm 0.18$ $6.84 \pm 0.12$. All films were found to be in the range of salivary $\mathrm{pH}$. The results are shown in Table 2 .

\section{Percentage moisture uptake}

The study of percentage moisture uptake and percentage moisture absorption gives the idea about the stability of the film in different environmental conditions. More the moisture absorption property of the film, less stable it will be. Percentage moisture uptake was found to be between $10.11 \pm 0.33 \%$ and $15.05 \pm 0.27 \%$. The results are shown in Table 2 .

\section{Drug content}

The prepared films were subjected to uniformity of drug content. Drug content of the films was found to be between $92.23 \pm 0.28 \%$ and $98.45 \pm 0.48 \%$. The observed result indicates that the drug was uniformly dispersed throughout the film. The results are shown in Table 2.

\section{DT}

Disintegration of orally fast-dissolving films was found to be in between $5.11 \pm 0.16 \mathrm{~s}$ and $8.13 \pm 0.26 \mathrm{~s}$.

\section{Folding endurance}

Folding endurance of orally fast-dissolving films was found to be in between 81 and 88 number of times.

\section{In vitro dissolution study}

Comparative dissolution profile of all batches is shown in Fig. 11. Formulation FDF5 showed faster drug release than other formulations. This may be due to hydrophilic polymer and propylene glycol that results in increased wettability and penetration of water into the film matrices and hence increased diffusion of the drug. Whereas, release rates of other formulation were comparatively slower. It was found that increase in the polymer concentration significantly decreased the drug release. The slow drug release mechanism for higher polymer concentration can be explained by reduction in permeability due to change in the morphology of the polymer. Increased polymer concentration may have provided the matrix with higher tortuosity and poor water porosity for diffusion of drug. Moreover, higher polymer concentration would have resulted in viscous environment of the system inhibiting movement of water into the matrix for easy diffusion of the drug into the surroundings. As the concentration of propylene glycol was decreased cumulative, $\%$ drug release from the films increased.

Comparative results of in vitro drug release of films made up of pullulan and hydroxypropyl methylcellulose HPMCE5

HPMC is known to be a polymer showing good film-forming properties. Hence, considering HPMC as a standard polymer, in vitro \% drug release between films made up of pullulan and HPMCE5 was compared. It was observed that in vitro $\%$ drug release from pullulan film was comparable with that of HPMC film as shown in Fig. 12.

\section{Ex vivo drug permeation studies}

Ex vivo permeation study results are shown in Fig. 13, wherein it is seen that $98.17 \%$ drug was permeated in $6 \mathrm{~min}$

\section{Stability study}

The optimized formulation (FDF5) was evaluated for stability studies which were stored at $40^{\circ} \mathrm{C} \pm 2{ }^{\circ} \mathrm{C} / 75 \% \pm 5 \% \mathrm{RH}$ for 2 months and were analyzed for physical appearance, DT, folding endurance, and in vitro $\%$ drug release rate after particular time interval. It was found that films retained its physical appearance and there was no much significant change in the values of DT, drug content, and in vitro \% drug release as shown in Table 3 
Table 2: Physicochemical characteristics of TMH film

\begin{tabular}{llllll}
\hline Formulation code & Surface pH & Thickness mm & Drug content (\%) & \% Moisture uptake & $\begin{array}{c}\text { DT (s) } \\
\text { (number of times) }\end{array}$ \\
\hline FDF1 & $6.67 \pm 0.08$ & $0.23 \pm 0.10$ & $94.70 \pm 0.24$ & $12.40 \pm 0.07$ & $6.24 \pm 0.35$ \\
FDF2 & $6.65 \pm 0.10$ & $0.17 \pm 0.11$ & $92.45 \pm 0.22$ & $14.92 \pm 0.49$ & $7.29 \pm 0.15$ \\
FDF3 & $6.80 \pm 0.14$ & $0.18 \pm 0.16$ & $92.23 \pm 0.28$ & $15.05 \pm 0.27$ & 81 \\
FDF4 & $6.76 \pm 0.18$ & $0.23 \pm 0.14$ & $94.46 \pm 0.4$ & $12.01 \pm 0.12$ & $8.05 \pm 0.24$ \\
FDF5 & $6.84 \pm 0.12$ & $0.17 \pm 0.11$ & $98.45 \pm 0.48$ & $10.11 \pm 0.33$ & 87 \\
FDF6 & $6.60 \pm 0.14$ & $0.18 \pm 0.20$ & $93.67 \pm 0.52$ & $14.13 \pm 0.58$ & $7.11 \pm 0.16$ \\
FDF7 & $6.53 \pm 0.18$ & $0.18 \pm 0.12$ & $94.67 \pm 0.56$ & $13.24 \pm 0.12$ & $7.13 \pm 0.12$ \\
FDF8 & $6.66 \pm 0.18$ & $0.29 \pm 0.16$ & $93.98 \pm 0.48$ & $14.13 \pm 0.40$ & $7.24 \pm 0.12$ \\
FDF9 & $6.79 \pm 0.12$ & $0.27 \pm 0.15$ & $96.54 \pm 0.58$ & $10.41 \pm 0.16$ & $8.13 \pm 0.26$ \\
\hline
\end{tabular}

Data represent mean \pm standard deviation, $\mathrm{n}=3$. TMH: Tramadol HCl, DT: Disintegration time

Table 3: Stability data of optimized formulation

\begin{tabular}{llll}
\hline Parameter & Initial & After 1 month & After $\mathbf{2}$ month \\
\hline Description & Transparent and smooth & Transparent and smooth & Transparent and smooth \\
DT (s) & $5.11 \pm 0.16$ & $4.49 \pm 0.18$ & $4.47 \pm 0.28$ \\
Folding endurance & $88 \pm 0.16$ & $87 \pm 0.18$ & $87 \pm 0.24$ \\
Drug content \% & 98.45 & 97.78 & 96.12 \\
\% CDR & $98.67 \pm 0.11$ & $97.67 \pm 0.23$ & $97.01 \pm 0.39$ \\
\hline
\end{tabular}

CDR: Cumulative drug release

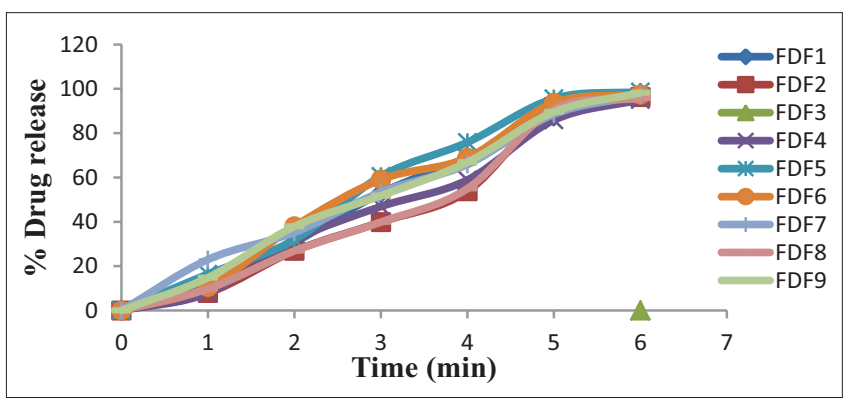

Fig. 11: In vitro release profile of TMH

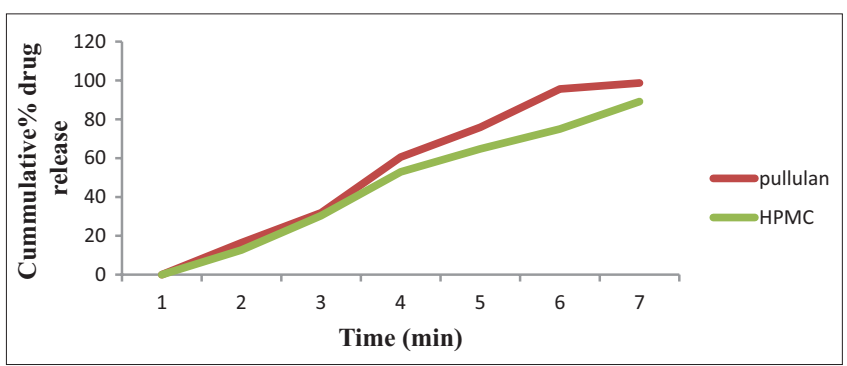

Fig. 12: Comparative results of in vitro drug release of Comparative results of in vitro drug release of films made up of pullulan and HPMCE5

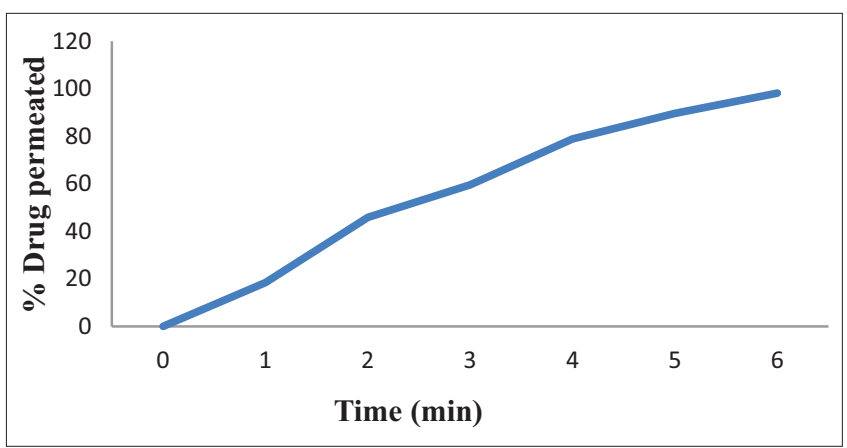

Fig. 13: Ex vivo drug permeation data of optimized formulation FDF5

\section{CONCLUSION}

Fast-dissolving oral thin films are intended for the application in the oral cavity and they are an innovative and promising dosage form, especially for use in pediatrics and geriatrics. The results of the present study indicated that pullulan could be used as a film-forming polymer for formulation of mouth dissolving film containing TMH. Acceptable mechanical properties were obtained in the batch FDF5 with in vitro DT of $5.11 \mathrm{~s}$. In vitro \% drug release from films made up of pullulan was found to be comparable with that of the films made up of HPMC which is known to be a good polymer for films. The optimized batch FDF5 was found to be stable for 2 months. Hence, it can be concluded that the fastdissolving wafers formulation using pullulan as natural biodegradable polymer can be an innovative and promising approach for the delivery of TMH, a centrally acting drug which needs fast onset of action in case of severe pain.

\section{ACKNOWLEDGMENT}

We acknowledge Zim Laboratories, Kalmeshwar, for providing gift sample of TMH and Gangwal Chemicals, Mumbai, for providing gift sample of polymer pullulan.

\section{AUTHORS' CONTRIBUTIONS}

Author Tejaswini Charde did the laboratory work of formulation, development, and evaluation of oromucosal wafer. Rita wadetwar is the author of correspondence. She supervised the whole work and prepared and corrected the manuscript.

\section{CONFLICT OF INTEREST}

The authors report no conflicts of interest. The authors alone are responsible for the content and writing of this article.

\section{REFERENCES}

1. Wadetwar RN, Chauhan C. Development of orodispersible tablet using Lepidium sativum seed mucilage as natural super disintegrant. Int J Chem Tech Res 2017;10:605-16.

2. Shahu SG, Wadetwar RN, Dixit GR. Development of microemulsion for solubility enhancement of poorly water-soluble drug Valsartan. Int J Pharm Sci Rev Res 2013;22:246-51.

3. Tomar A, Sharma K, Chauhan NS, Mittal A, Bajaj U. Formulation and evaluation of fast dissolving oral film dicylomine as potential route of buccal delivery. Int J Drug Dev Res 2012;4:408-17.

4. Desai P, Basu B. Design and evaluation of fast dissolving film of 
domperidone. Int J Pharm 2012;3:134-45.

5. Haywood A, Glass BD. Liquid dosage forms extemporaneously prepared from commercially available products-considering new evidence on stability. J Pharm Pharm Sci 2013;1:441-55.

6. Fu Y, Yang S, Jeong SH. Orally fast disintegrating tablets: Development technologies, taste-masking and clinical studies. Crit Rev Theory Drug Carrier Syst 2004;2:433-75.

7. Nalluri BN, Sravan IB, Saisri AV, Sribramhini R, Maheswari KM. Development and evaluation of mouth dissolving films of sumatriptan succinate for better therapeutic efficacy. J Appl Pharm Sci 2013;3:161-6.

8. Dev P, Maiti S. Orodispersible tablets: A new trend in drug delivery. J Natl Sci Biomed 2010;5:126-8.

9. Daud A, Peepliwal A, Bonde M, Sapkal N, Gaikwad N. Design and development of Nicotiana tabacum film using factorial design. Int $\mathbf{J}$ Pharm Pharm Sci 2016;8:115-23.

10. Patel NK, Pancholi SS. An overview on sublingual route for systemic drug delivery. Int J Res Pharm Biomed Sci 2012;3:913-23.

11. Hariharn M, Bogue A. Orally dissolving film strips (ODFS): The final evolution of orally dissolving dosage forms. Drug Deliv Technol 2009;6:24-7.

12. Suzuki H, Onishi H, Takahashi Y. Development of oral Acetaminophen chewable tablets with inhibited bitter taste. Int J P Pharm 2003;2:123-32.

13. Prajapati V, Bansal M, Sharma PK. Mucoadhesive buccal patches and use of natural polymer in its preparation-a review. Int J PharmTech Res 2012;4:582-9.

14. Kaur N, Nirmala H, Kumar SL. Review on study of buccal patches: Current status of formulation and evaluation methods. J Drug Delivery Ther 2014;4:69-79.

15. Ghada EY, Haidy AB. Design and evaluation of fast dissolving oro-dispersible films of metoclopramide hydrochloride using 32 multifactorial designs. Int J Pharm Pharm Sci 2016;8:218-22.

16. Mahajan RK, Sonje H, Birari A, Yadav G, Maru A. Design, formulation and evaluation of mouth dissolving films of Rizatriptan by solvent casting method. World J Pharm Res 2015;7:614-22.

17. Koland M. Fast dissolving sublingual films of ondansetron hydrochloride: Effect of additives on in vitro drug release and mucosal permeation. J Young Pharm 2010;2:216-22.

18. Maniruzzamam M, Boateng J, Bennefill M. Taste masking of paracetamol by holt-melt extrusion: Animino and in vitro evaluation. Eur J pharma Biopharm 2012;8:433-42.

19. Sumitha CH, Varma MV, Sriniwas K. Development of taste masked fast dissolving orally consumable films of seldinafil citrate. IJPIs J Pharma Cosmet 2011:1:1-6.

20. Rao NR, Reddy SK, Swapna D, Konasree SD, Enugala S. Formulation and evaluation of rapidly dissolving buccal patches. Int J Pharm Bio Sci 2011;1:145-59. 